CLINICAL STUDY

\title{
Relationship of adiposity with arterial stiffness as mediated by adiponectin in older men and women: the Hoorn Study
}

\author{
M B Snijder ${ }^{1,2}$, A Flyvbjerg ${ }^{3}$, C D A Stehouwer ${ }^{4}$, J Frystyk ${ }^{3}$, R M A Henry ${ }^{4}$, J C Seidell ${ }^{1,2}$, R J Heine ${ }^{2}$ and J M Dekker ${ }^{2}$ \\ ${ }^{1}$ Department of Health Sciences, VU University Amsterdam, De Boelelaan 1085, $1081 \mathrm{HV}$ Amsterdam, The Netherlands, ${ }^{2}$ EMGO Institute, VU \\ University Medical Center, Amsterdam, The Netherlands, ${ }^{3}$ The Medical Research Laboratories, Clinical Institute, Aarhus University Hospital, Aarhus C, \\ Denmark and ${ }^{4}$ Department of Internal Medicine, Academic Hospital Maastricht, Maastricht, The Netherlands \\ (Correspondence should be addressed to M B Snijder; Email: marieke.snijder@falw.vu.nl)
}

\begin{abstract}
Objective: To investigate whether adiponectin is associated with arterial stiffness, and whether adiponectin explains the association between body composition and arterial stiffness.

Design: Cross-sectional cohort study.

Methods: Subjects were participants $(n=456$, mean age $68.9 \pm 6.1$ years; age range $60-86$ years $)$ of the third follow-up examination of the Hoorn Study. Trunk fat, leg fat, trunk lean, and leg lean mass were measured by dual-energy X-ray absorptiometry. Ultrasound was used to measure distensibility and compliance of the carotid, femoral, and brachial arteries, and carotid Young's elastic modulus (as estimates of peripheral arterial stiffness).

Results: Trunk fat mass was negatively associated with (ln-transformed) adiponectin (standardized $\beta=-0.49, P<0.001)$, while leg fat mass was positively associated with adiponectin $(\beta=0.44$, $P<0.001$ ), after adjustment for each other, age, and lean mass. After adjustment for age, sex, mean arterial pressure, and estimated glomerular filtration rate, higher adiponectin was associated with decreased peripheral arterial stiffness ( $\beta$ of mean Z-scores of all three arteries $=0.14, P=0.001$ ). However, the associations of trunk fat $(\beta=-0.26, P<0.001)$ and leg fat $(\beta=0.16, P=0.006)$ with peripheral arterial stiffness were only minimally explained by adiponectin levels.

Conclusion: Trunk fat and leg fat are oppositely associated with adiponectin. Although low adiponectin was a determinant of increased peripheral arterial stiffness, it only explained a small part of the association between body fat and peripheral arterial stiffness. This indicated that factors other than adiponectin may be more important in the pathophysiological mechanisms by which abdominal obesity leads to arterial stiffness.
\end{abstract}

European Journal of Endocrinology 160 387-395

\section{Introduction}

Obesity, particularly abdominal obesity, is a strong risk factor for cardiovascular disease (CVD) (1). Arterial stiffness is a strong predictor of CVD and is considered to be an early marker of CVD, as it impairs the ability of the arterial system to handle the pressure boost at systole. This leads to increased systolic blood pressure, decreased diastolic blood pressure, increased left ventricular mass, and decreased diastolic perfusion (2). We have previously shown that regional fat distribution is associated with peripheral arterial stiffness (and not with central arterial stiffness). Trunk fat mass was associated with increased peripheral arterial stiffness, whereas leg fat was independently associated with decreased arterial stiffness $(3,4)$.

The underlying pathophysiological mechanisms linking fat distribution to CVD are not completely understood, but proteins secreted by adipose tissue (adipokines) are thought to be involved (5). Adiponectin is a promising adipokine, which is predominantly produced by adipocytes and the most abundant adipocyte-derived protein. Paradoxically, adiponectin levels are decreased in (abdominal) obesity (6). The differences in the effects of trunk and leg fat on arterial stiffness (4), as well as on other cardiovascular risk estimates $(7,8)$, may be explained by differential secretion of adipokines by different fat depots.

Several studies have shown that adiponectin has insulin-sensitizing, anti-inflammatory, and anti-atherosclerotic properties $(9,10)$. Adiponectin inhibits the expression of adhesion molecules in human endothelial cells and suppresses macrophage function, and thus plaque formation. It may also limit cardiac remodeling $(10,11)$. Only very few relatively small studies in selected populations investigated adiponectin in relation to arterial stiffness and had inconsistent results (12-15). To our knowledge, no study has investigated the potential role of adiponectin in the relationship between precisely measured fat distribution and arterial stiffness. 
The aims of the present study were to investigate the association of adiponectin levels with peripheral arterial stiffness and to study to what extent adiponectin concentrations could explain the association of body composition with peripheral arterial stiffness in a large population-based study of older men and women.

\section{Methods}

\section{Subjects}

Subjects for the present study were participants of the Hoorn Study. The Hoorn Study commenced in 1989 and is a population-based cohort study of glucose metabolism and its consequences (16). At baseline, 2484 men and women aged 50-75 years were included. In 2000-2001, a third examination was carried out among surviving participants who gave their permission to be re-contacted. All participants who had diabetes at the second examination in 19961998 (17), as determined by a $75 \mathrm{~g}$ oral glucose tolerance test (OGTT) or by diabetes treatment $(n=176)$, were invited. We also invited a random sample of participants who had normal glucose tolerance $(n=705)$ or impaired glucose tolerance $(n=193)$ at the second examination in 1996-1998. Of 1074 persons invited, $648(60.3 \%)$ participated. The main reasons for not participating in the 20002001 follow-up examination were lack of interest $(30 \%)$ or comorbidity $(23 \%)$. Other reasons were high age $(7 \%)$, unwillingness to travel $(6 \%)$, participation considered too time-consuming $(6 \%)$, and miscellaneous reasons $(15 \%)$, while $13 \%$ gave no reason. For the present study, cross-sectional data of this examination were analyzed. The Ethical Review Committee of the VU University Medical Center approved the study protocol and all participants gave their written informed consent.

\section{Adiponectin}

At the medical examination, a blood sample was taken from all participants after overnight fasting. Total adiponectin was determined in 2006 in spare plasma samples that had been stored at $-80{ }^{\circ} \mathrm{C}$. Adiponectin concentrations $(\mathrm{mg} / \mathrm{l})$ were determined by an in-house time-resolving immunofluorometric assay as recently described (18). After 80 setups, the inter-assay coefficient of variation $(\mathrm{CV})$ of internal quality control solutions containing recombinant human adiponectin averaged $7.75,7.88$, and $6.96 \%$ at a level of $3.4,17.4$, and $174.0 \mathrm{mg} / \mathrm{l}$ respectively. The inter-assay $\mathrm{CV}$ of a human quality control serum sample averaged $9.24 \%$ (76 setups, mean $13.12 \pm 1.21 \mathrm{mg} / \mathrm{l}$ ). The intra-assay $\mathrm{CV}$ of unknown samples analyzed in duplicate averaged $2.0 \%$.

\section{Body composition}

Total body fat percent, and fat and lean soft tissue mass of the trunk and legs were determined by whole body dual-energy X-ray absorptiometry (DXA) (QDR-2000, software version 7.20D, Hologic, Brussels, Belgium). Trunk fat and leg fat were partitioned according to specific anatomic landmarks, as has been described for the Hoorn Study previously (8). All DXA scans were performed and read by one investigator.

\section{Arterial stiffness}

In the Hoorn Study, both the central and peripheral arterial stiffness has been measured $(19,20)$. Because fat distribution was not associated with central arterial stiffness (as estimated by carotid-femoral transit time, aortic augmentation index, and systemic arterial compliance (4)), and central arterial stiffness estimates were not associated with adiponectin levels (data not shown), we will only describe methods and results for peripheral arterial stiffness.

The methods used to estimate peripheral arterial stiffness have been described in detail previously (20). Briefly, we obtained the diameter (D) and distension $(\Delta \mathrm{D})$ of the right common carotid, the right common femoral, and the right brachial arteries, and the intimamedia thickness (IMT) of the right carotid artery by ultrasound. Brachial systolic and diastolic pressures were assessed in the left upper arm. Brachial pulse pressure (PP) and brachial mean arterial pressure were calculated. PP at the carotid and femoral arteries was calculated by the distension waveform calibration method, which is more accurate than using brachial PP $(21,22)$. All ultrasound measurements were performed by a single sonographer.

Distensibility coefficient (DC) end compliance coefficients (CC) were calculated from D, $\Delta \mathrm{D}$, and PP (23). Distensibility reflects the elastic properties of an artery whereas the compliance reflects the buffering capacity of the artery. Lower values of DC and CC indicate stiffer arteries. From carotid IMT, D, and DC, we calculated Young's elastic modulus (E), an estimate of the intrinsic elastic properties of the vessel wall. Lower values of $\mathrm{E}$ indicate less stiff arteries.

\section{Additional measurements}

We determined fasting glucose, insulin, $2 \mathrm{~h}$ post-load glucose after a $75 \mathrm{~g}$ OGTT, fasting high-density lipoprotein (HDL) and low-density lipoprotein (LDL) cholesterol, triglycerides, serum creatinine, body mass index (BMI), waist circumference, and prior CVD as described elsewhere $(8,24,25)$.

Because renal function may influence adiponectin levels (15), renal function was estimated by the glomerular filtration rate (eGFR) by the modification 
of diet in renal disease (MDRD) equation $(170 \times$

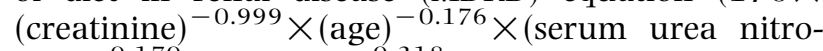
gen $)^{-0.170} \times(\text { albumin })^{0.318} \times(0.762$ if patient is female; 1.180 if patient is black)) (26). The MDRD equation is given in traditional units. To convert to International System units, multiply creatinine in $\mathrm{mg} / \mathrm{dl}$ by 88.4 , urea in $\mathrm{mg} / \mathrm{dl}$ by 0.357 , and albumin in $\mathrm{g} / \mathrm{dl}$ by 10. eGFR is expressed in $\mathrm{ml} / \mathrm{min}$ per $1.73 \mathrm{~m}^{2}$ body surface area.

We obtained self-reported information on health status, medical history, current medication use, physical activity (min/week), alcohol intake (g/day), macronutrient intake (energy \%), and current smoking (yes/no) by questionnaires.

\section{Statistical analyses}

Baseline characteristics of the study population are shown according to sex-specific tertiles of adiponectin levels in order to show crude associations with this hormone. Associations between body composition measures (trunk fat, trunk lean, leg fat, and leg lean mass), adiponectin, and peripheral arterial stiffness were investigated by linear regression analyses. Standardized $\beta$ values are reported. A standardized $\beta$ of 0.1 indicates that when the independent variable increases by 1 S.D., the dependent variable increases by 0.1 s.D.

First, we considered trunk fat, trunk lean, leg fat, and leg lean mass together as determinants (independent variables) of adiponectin concentration (dependent variable), adjusted for age and additionally adjusted for eGFR, and lifestyle factors (smoking and dietary intakes of fat and carbohydrates).

Next, we investigated the associations between adiponectin (independent variable) and peripheral arterial stiffness estimates (distensibility and compliance of the carotid, femoral and brachial arteries, and the carotid Young's elastic modulus; dependent variables). A summarizing peripheral stiffness variable was constructed by means of Z-scores. We calculated (sex specific) Z-scores for each peripheral stiffness measure (DC, CC, and E) of each artery, and multiplied the Z-score of E by -1 . A Z-score is calculated as the individual value minus the mean value in the study population, divided by the S.D. We also performed regression analyses using the mean of the seven Z-scores as a dependent variable.

Finally, it was investigated whether adiponectin, in part, explained the associations between body composition measures and peripheral arterial stiffness by adding this variable to the regression model, which included body composition measures as independent and peripheral arterial stiffness as dependent variables.

In all regression models, effect modification by gender, prior CVD or presence of type 2 diabetes was tested by adding product terms to the models. Effect modification was considered statistically significant if $P<0.10$. We considered the stability of the regression models to be disturbed by multicollinearity if the tolerance was $<0.1$ (or variance inflation factor $>10$ ). The correlation between trunk fat and leg fat was 0.522 . None of the reported regression models was disturbed by multicollinearity. All statistical analyses were performed using SPSS for Windows (version 10.1.0; Chicago, IL, USA).

\section{Results}

Of the 648 participants, 25 had missing DXA data and for 37 persons adiponectin levels could not be determined due to lack of plasma (nine participants missed both). From the remaining 595 participants, another 139 participants did not take part in the ultrasound examination and were excluded from all analyses. The main reason for missing ultrasound data was poor definition of the arterial wall due to obesity (20). The final study sample consisted of 456 participants.

Baseline characteristics of the study population are shown in Table 1 according to sex-specific tertiles of adiponectin levels. From the lifestyle variables, smoking was inversely associated with adiponectin levels in women only. In men, physical activity was positively associated with adiponectin, whereas a negative association was observed in women. Although a consistent negative association was observed between adiponectin and type 2 diabetes, a positive association was shown between adiponectin and prior CVD in women. Interestingly, a strong negative association between BMI and adiponectin was observed, whereas total body fat percent was not statistically significantly associated. This may be caused by opposite effects of different types of body fat, which is addressed in Table 2. In this Table, it is shown that a larger trunk fat mass was associated with lower adiponectin levels independently of trunk lean, leg fat, and leg lean mass, whereas larger leg fat was independently associated with higher adiponectin levels. Although in Model 1 of Table 2 a statistically significant effect modification by sex was found for both trunk fat $(P=0.091)$ and leg fat $(P=0.045)$, results were very similar for men and women when the analyses were stratified for sex. Also in Fig. 1 it is shown that, although absolute adiponectin concentrations differ between sexes, the associations of trunk and leg fat with adiponectin concentrations were similar. Leg lean mass (mostly muscle mass) did not significantly contribute to adiponectin levels after adjustment for fat masses (Table 2). Adjustment for kidney function and for lifestyle factors (which were associated with adiponectin; see Table 1) did not change these results.

Adiponectin was not associated with the measures of central arterial stiffness (data not shown). The associations of adiponectin levels with the various estimates of peripheral arterial stiffness, and with the summarizing variable of these estimates, are shown in Table 3. Overall, higher adiponectin levels were associated with 
Table 1 Characteristics according to sex-specific tertiles of adiponectin.

\begin{tabular}{|c|c|c|c|c|c|c|c|c|c|c|}
\hline & \multicolumn{3}{|c|}{ Men } & \multirow[b]{2}{*}{$P$ trend } & \multirow[b]{2}{*}{$P$ adj age } & \multicolumn{3}{|c|}{ Women } & \multirow[b]{2}{*}{$P$ trend } & \multirow[b]{2}{*}{$P$ adj age } \\
\hline & $1(n=76)$ & $2(n=77)$ & $3(n=76)$ & & & $1(n=75)$ & $2(n=76)$ & $3(n=76)$ & & \\
\hline Adiponectin (mg/l) & $5.32 \pm 1.13$ & $8.08 \pm 0.77$ & $12.8 \pm 2.7$ & - & - & $8.24 \pm 1.90$ & $13.48 \pm 1.31$ & $21.80 \pm 7.43$ & - & - \\
\hline Age (years) & $67.7 \pm 5.7$ & $68.5 \pm 5.7$ & $70.2 \pm 6.0$ & 0.008 & - & $68.5 \pm 6.1$ & $68.7 \pm 6.0$ & $69.5 \pm 6.9$ & 0.333 & - \\
\hline eGFR $\left(\mathrm{ml} / \mathrm{min}\right.$ per $\left.1.73 \mathrm{~m}^{2}\right)$ & $69.4 \pm 9.6$ & $68.0 \pm 12.5$ & $69.1 \pm 12.7$ & 0.874 & 0.684 & $62.1 \pm 7.9$ & $60.3 \pm 7.2$ & $64.3 \pm 7.3$ & 0.078 & 0.053 \\
\hline $\operatorname{MAP}(\mathrm{mmHg})$ & $97.7 \pm 10.0$ & $97.2 \pm 9.9$ & $97.3 \pm 10.2$ & 0.789 & 0.449 & $97.0 \pm 11.1$ & $95.9 \pm 11.7$ & $99.0 \pm 13.7$ & 0.318 & 0.432 \\
\hline Prior CVD (\%) & 44.7 & 43.2 & 42.7 & 0.797 & 0.357 & 39.7 & 46.1 & 48.0 & 0.313 & 0.010 \\
\hline $\mathrm{DM}(\%)$ & 25.0 & 19.5 & 13.2 & 0.066 & 0.028 & 32.0 & 13.2 & 9.5 & 0.001 & 0.000 \\
\hline \multicolumn{11}{|l|}{ Body composition } \\
\hline BMl $\left(\mathrm{kg} / \mathrm{m}^{2}\right)$ & $27.2 \pm 2.7$ & $26.2 \pm 2.8$ & $25.8 \pm 2.9$ & 0.003 & 0.003 & $26.9 \pm 3.0$ & $26.0 \pm 3.0$ & $25.7 \pm 3.0$ & 0.010 & 0.011 \\
\hline Waist circumference $(\mathrm{cm})$ & $99.4 \pm 8.3$ & $96.5 \pm 9.4$ & $96.0 \pm 9.2$ & 0.020 & 0.013 & $91.0 \pm 8.5$ & $86.4 \pm 8.7$ & $84.8 \pm 10.3$ & 0.000 & 0.000 \\
\hline WHR & $0.98 \pm 0.06$ & $0.97 \pm 0.06$ & $0.96 \pm 0.07$ & 0.048 & 0.023 & $0.88 \pm 0.06$ & $0.85 \pm 0.06$ & $0.83 \pm 0.08$ & 0.000 & 0.000 \\
\hline Body fat (\%) & $27.6 \pm 5.5$ & $27.3 \pm 5.9$ & $26.9 \pm 6.2$ & 0.488 & 0.308 & $40.4 \pm 5.3$ & $40.1 \pm 6.2$ & $39.1 \pm 6.7$ & 0.182 & 0.166 \\
\hline Trunk fat $(\mathrm{kg})$ & $12.9 \pm 4.5$ & $12.1 \pm 4.5$ & $11.1 \pm 4.6$ & 0.014 & 0.011 & $14.7 \pm 4.1$ & $13.0 \pm 4.3$ & $11.9 \pm 4.6$ & 0.000 & 0.000 \\
\hline Leg fat $(\mathrm{kg})$ & $6.2 \pm 1.6$ & $6.1 \pm 1.9$ & $6.4 \pm 1.8$ & 0.354 & 0.534 & $9.5 \pm 2.5$ & $10.3 \pm 3.0$ & $10.2 \pm 2.7$ & 0.099 & 0.081 \\
\hline Trunk lean (kg) & $28.6 \pm 3.1$ & $27.5 \pm 2.7$ & $27.4 \pm 2.7$ & 0.010 & 0.015 & $20.6 \pm 2.2$ & $19.9 \pm 2.3$ & $19.9 \pm 2.1$ & 0.047 & 0.070 \\
\hline Leg lean $(\mathrm{kg})$ & $18.1 \pm 2.4$ & $17.3 \pm 2.1$ & $17.1 \pm 2.2$ & 0.005 & 0.002 & $12.7 \pm 1.7$ & $12.3 \pm 1.9$ & $12.1 \pm 1.8$ & 0.055 & 0.081 \\
\hline \multicolumn{11}{|l|}{ Lifestyle } \\
\hline Current smoking (\%) & 18.4 & 20.8 & 18.4 & 1.000 & 0.942 & 20.0 & 13.2 & 5.3 & 0.009 & 0.010 \\
\hline Physical activity (min/week) & $\begin{array}{l}1035 \\
\quad(600-1650)\end{array}$ & $\begin{array}{l}1150 \\
\quad(533-2010)\end{array}$ & $\begin{array}{l}1178 \\
\quad(709-1800)\end{array}$ & 0.419 & 0.199 & $\begin{array}{l}1470 \\
(820-2100)\end{array}$ & $\begin{array}{l}1380 \\
\quad(938-2220)\end{array}$ & $\begin{array}{l}1260 \\
(805-1763)\end{array}$ & 0.369 & 0.399 \\
\hline Alcohol use (\% yes) & 98.7 & 96.1 & 98.7 & 1.000 & 0.975 & 91.9 & 94.5 & 94.7 & 0.476 & 0.362 \\
\hline Alcohol intake (g/day) & $11.7(2.4-29.1)$ & $14.5(2.2-28.4)$ & $11.7(4.1-31.6)$ & 0.627 & 0.513 & $2.9(0.2-14.0)$ & $4.7(0.7-11.6)$ & $2.9(0.7-11.9)$ & 0.433 & 0.446 \\
\hline Fat intake (\% energy intake) & $36.2 \pm 5.6$ & $35.7 \pm 5.2$ & $33.8 \pm 6.0$ & 0.010 & 0.016 & $34.5 \pm 5.1$ & $34.2 \pm 5.9$ & $33.1 \pm 6.1$ & 0.146 & 0.151 \\
\hline $\begin{array}{l}\text { Carbohydrate intake (\% energy } \\
\text { intake) }\end{array}$ & $42.5 \pm 6.4$ & $44.7 \pm 5.6$ & $45.0 \pm 6.9$ & 0.014 & 0.029 & $46.6 \pm 6.9$ & $46.4 \pm 6.2$ & $47.1 \pm 6.9$ & 0.619 & 0.689 \\
\hline
\end{tabular}

eGFR, estimated glomerular filtration rate; MAP, mean arterial pressure; CVD, cardiovascular disease; DM, type 2 diabetes mellitus; BMI, body mass index; WHR, waist-to-hip ratio. 
Table 2 Independent associations of trunk fat, trunk lean, leg fat, and leg lean mass (adjusted for each other) with In-transformed adiponectin levels.

\begin{tabular}{|c|c|c|c|c|c|c|}
\hline & \multicolumn{3}{|c|}{ Men } & \multicolumn{3}{|c|}{ Women } \\
\hline & B & $95 \% \mathrm{Cl}$ & $P$ value & B & $95 \% \mathrm{Cl}$ & $P$ value \\
\hline \multicolumn{7}{|l|}{ Model 1} \\
\hline Trunk fat mass & -0.49 & -0.66 to -0.32 & 0.000 & -0.49 & -0.63 to -0.35 & 0.000 \\
\hline Trunk lean mass & -0.19 & -0.41 to 0.02 & 0.076 & -0.05 & -0.25 to 0.15 & 0.611 \\
\hline Leg fat mass & 0.45 & 0.27 to 0.62 & 0.000 & 0.44 & 0.30 to 0.58 & 0.000 \\
\hline Leg lean mass & -0.04 & -0.26 to 0.17 & 0.689 & -0.05 & -0.26 to 0.17 & 0.603 \\
\hline \multicolumn{7}{|l|}{ Model 2} \\
\hline Trunk fat mass & -0.49 & -0.66 to -0.32 & 0.000 & -0.49 & -0.63 to -0.36 & 0.000 \\
\hline Trunk lean mass & -0.19 & -0.41 to 0.02 & 0.076 & -0.05 & -0.25 to 0.15 & 0.611 \\
\hline Leg fat mass & 0.45 & 0.27 to 0.62 & 0.000 & 0.45 & 0.30 to 0.59 & 0.000 \\
\hline Leg lean mass & -0.04 & -0.26 to 0.17 & 0.706 & -0.03 & -0.24 to 0.17 & 0.767 \\
\hline \multicolumn{7}{|l|}{ Model 3} \\
\hline Trunk fat mass & -0.49 & -0.67 to -0.31 & 0.000 & -0.49 & -0.63 to -0.35 & 0.000 \\
\hline Trunk lean mass & -0.19 & -0.39 to 0.04 & 0.117 & -0.01 & -0.21 to 0.19 & 0.943 \\
\hline Leg fat mass & 0.44 & 0.26 to 0.62 & 0.000 & 0.43 & 0.29 to 0.57 & 0.000 \\
\hline Leg lean mass & -0.06 & -0.28 to 0.16 & 0.574 & -0.06 & -0.27 to 0.14 & 0.548 \\
\hline
\end{tabular}

Model 1, adjusted for age; Model 2, adjusted for age and eGFR; Model 3, adjusted for age, eGFR, and lifestyle factors (smoking and dietary intakes of fat and carbohydrates) $\mathrm{B}$, standardized $\beta$; $\mathrm{Cl}$, confidence interval; eGFR, estimated glomerular filtration rate.

less stiff arteries. It is also shown, however, that the associations with stiffness estimates at the brachial artery were not statistically significant, although they were in the same direction when compared with femoral and carotid arteries. Men and women were analyzed together because for each of the stiffness estimates there was no statistically significant effect modification by sex ( $P$ interaction for the mean Z-score was 0.331). Additional adjustment for eGFR did not change the results (Model 2), nor did adjustment for height (data not shown). Although effect modification by prior CVD $(n=198)$ or presence of type 2 diabetes $(n=85)$ was not statistically significant, the associations between adiponectin and peripheral arterial stiffness were weaker in subjects who experienced prior CVD ( $\beta$ of mean Z-score 0.10, $P=0.154$ ) and not evident in whom type 2 diabetes was present ( $\beta$ of mean Z-score 0.05, $P=0.579$ ), when compared with subject without prior CVD ( $\beta$ of mean Z-score 0.18 , $P=0.003$ ) or without type 2 diabetes ( $\beta$ of mean Z-score $0.11, P=0.036$ ).

Table 4 shows associations of body composition with peripheral arterial stiffness estimates. Larger trunk fat mass was associated with increased peripheral arterial stiffness, whereas larger leg fat mass was associated with less stiffening (as reported before by Snijder et al. (4)). There was no statistically significant effect modification of these associations by gender (all $P>0.10)$. So, although associations were found between trunk and leg fat masses and adiponectin (Table 2), and adiponectin was associated with peripheral arterial stiffness (Table 3), adiponectin only explained a very small part of the associations between body composition and peripheral arterial stiffness (Model 2, Table 4).

\section{Discussion}

Our study showed that i) body composition is a strong determinant of adiponectin levels, with trunk fat associated with lower adiponectin levels and leg fat
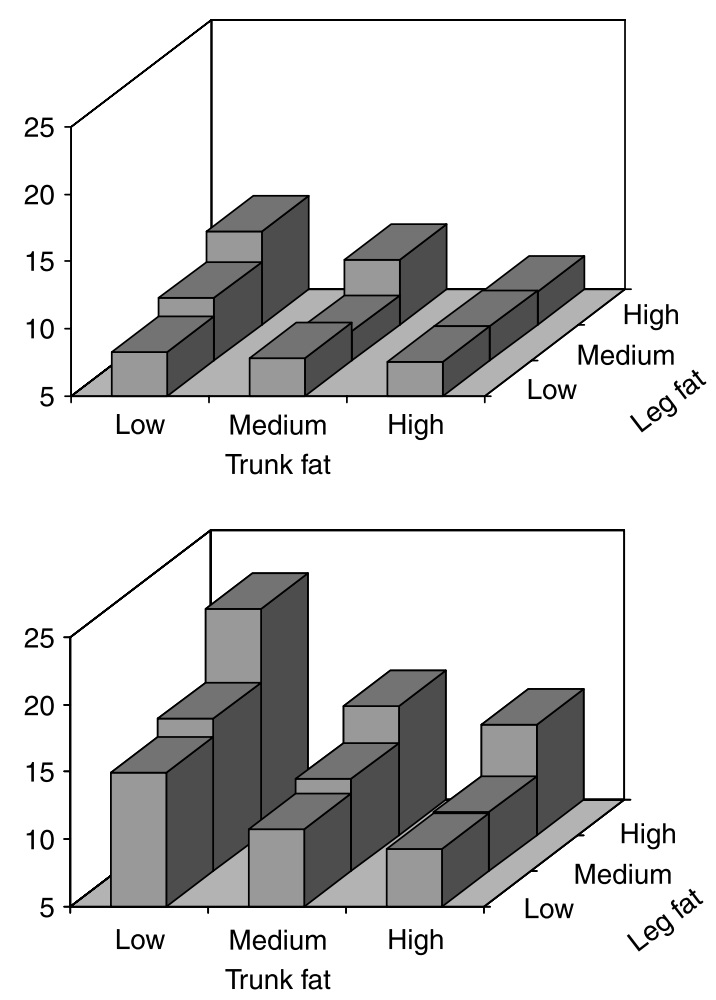

Figure 1 Age-adjusted geometric mean adiponectin levels $(\mathrm{mg} / \mathrm{l})$ within tertiles of trunk and leg fat mass in men (left) and women (right). 
Table 3 Associations (standardized $\beta, P$ value) of In-transformed adiponectin concentrations with peripheral arterial stiffness estimates.

\begin{tabular}{|c|c|c|c|c|c|c|c|c|}
\hline & \multicolumn{3}{|c|}{ Carotid } & \multicolumn{2}{|c|}{ Femoral } & \multicolumn{2}{|c|}{ Brachial } & \multirow{2}{*}{$\begin{array}{c}\text { All } \\
\text { Mean Z-score }\end{array}$} \\
\hline & DC & $\mathrm{CC}$ & $E$ & DC & $\mathrm{CC}$ & $\mathrm{DC}$ & $\mathrm{CC}$ & \\
\hline Model 1 & $0.127(0.003)$ & $0.062(0.192)$ & $-0.089(0.053)$ & $0.187(0.000)$ & $0.149(0.002)$ & $0.062(0.240)$ & $0.009(0.868)$ & $0.143(0.001)$ \\
\hline Model 2 & $0.122(0.004)$ & $0.055(0.247)$ & $-0.086(0.064)$ & $0.191(0.000)$ & $0.153(0.002)$ & $0.058(0.268)$ & $0.006(0.901)$ & $0.140(0.002)$ \\
\hline
\end{tabular}

Model 1, adjusted for age, sex, and MAP; Model 2, model 1 adjusted for eGFR; DC, distensibility coefficient; CC, compliance coefficient; E, Young's elastic modulus; MAP, mean arterial pressure; eGFR, estimated glomerular filtration rate.

associated with higher levels, ii) low adiponectin levels are associated with increased peripheral arterial stiffness, particularly at the femoral and carotid arteries, and iii) adiponectin levels, however, only explained a small part of the associations between body composition and peripheral arterial stiffness.

Although the negative association between overall obesity, as estimated by BMI and adiponectin levels, is quite consistent in numerous studies, the association between DXA-measured body fat mass or body fat percentage and adiponectin has been found to be less consistent $(27,28)$. Regarding fat distribution, waist circumference or waist-to-hip ratio were stronger and negatively associated with adiponectin than BMI $(6,27$, 29), and CT-measured visceral fat was a stronger negative determinant than abdominal s.c. fat $(30,31)$. One study revealed that waist-to-hip ratio was even more strongly associated with adiponectin than visceral fat tissue (6), which may be due to the additional effect of femoral-gluteal fat tissue (measured by hip circumference) on adiponectin levels. To our knowledge, only few studies have investigated regional fat distribution by DXA in relation to adiponectin levels in adults, one in men (32) and two in women $(33,34)$. Consistent with our findings, it was found that lower body fat was positively associated with adiponectin levels $(32,33)$. In the third study, the androidal-to-gynoidal fat mass ratio assessed via DXA accounted for the greatest part of the variability in adiponectin levels (34). An explanation for the different associations of trunk and leg fat with adiponectin levels may be that these fat depots may differ in adiponectin secretion rate. Differences in adiponectin secretion in human cells from intraabdominal fat compared with abdominal s.c. fat have been shown (35), but less is known about adiponectin secretion by femoral-gluteal adipocytes.

Only few studies have investigated the association between adiponectin levels and arterial stiffness (1215). Compared with the present study, these studies were relatively small and they were usually performed in a selected group of subjects, which may explain why inconsistent results were found in previous studies. Stork et al. investigated a selection of women with an increased IMT, and found that low adiponectin was associated with worsening of carotid DC (12). Adiponectin was also associated with a carotid stiffness index in subjects without diabetes, but not in diabetes patients (13). In 75 never-treated hypertensive patients, low adiponectin was associated with not only increased central stiffness (by pulse wave velocity), but also decreased central stiffness (by augmentation index) (14). Finally, Tentolouris et al. did not find an association between adiponectin and aortic distensibility in patients with chronic renal failure or controls (15).

The latter two studies $(14,15)$ investigated estimates of central stiffness, and found no or inconsistent associations, which may be in line with our findings that none of the estimates of central stiffness were associated with adiponectin levels. The other two studies $(12,13)$ investigated the markers of carotid arterial stiffness and found an association with adiponectin, except in diabetes patients. We extend these observations by studying a population-based cohort of elderly subjects, and investigating a large set of arterial stiffness estimates, including stiffness estimates at the femoral and brachial arteries, in addition to the carotid artery.

There may also be another or additional explanation for inconsistent results of adiponectin in relation to arterial stiffness in previous studies. Although adiponectin has been suggested to protect against CVD (36), prospective studies are not consistent and even find opposite associations (37-39). In addition, adiponectin was not (or was even positively) associated with either all-cause mortality or CVD mortality in patients with end-stage renal disease, congestive heart failure, or coronary artery disease (40-43) as well as in the general population (44-46). The underlying mechanisms are not exactly understood, but it has been suggested that the increased inflammatory state of these patients may trigger a compensatory increase of adiponectin in an attempt to limit further endothelial damage, cardiac remodeling or atherosclerotic change $(10,47,48)$. This would be consistent with our findings that associations between adiponectin and peripheral arterial stiffness are not significant in persons who had prior CVD or in whom type 2 diabetes was present (persons who are at an increased inflammatory state). In addition, circulating adiponectin exists in high, middle, and low molecular weight isoforms. High molecular weight (HMW) adiponectin has been suggested to be the biologically most active form of adiponectin. The percentage of biologically active HMW adiponectin may still be decreased in the chronic CVD conditions, despite high levels of total adiponectin, due 


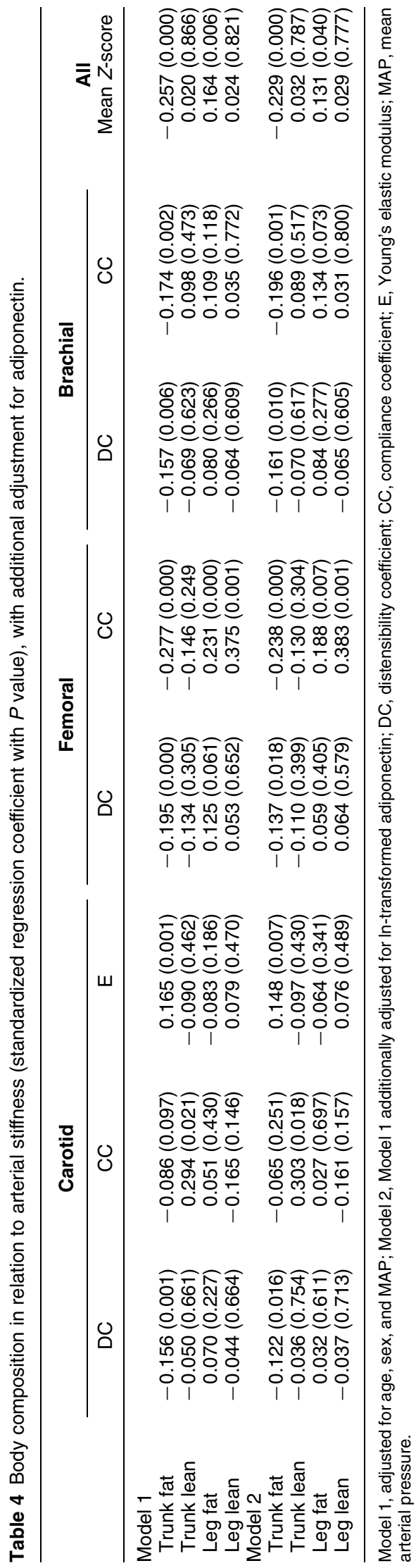

to impaired multimerization of inert adiponectin complexes into HMW adiponectin $(47,48)$. So, adiponectin isomer distribution may explain the paradoxical association of adiponectin with mortality and also the inconsistent results with arterial stiffness. Therefore, measurement of adiponectin isomer fractions is recommended in future epidemiological studies.

Despite clear associations between fat depots and adiponectin, and between adiponectin and peripheral arterial stiffness, adiponectin did not explain a large part of the associations between fat depots and arterial stiffness. To the best of our knowledge, this has not been studied before. These results indicate that adiponectin probably does not play an important causal role in the association of abdominal obesity with the stiffening of the arteries. Other factors, such as inflammatory factors, other proteins secreted by adipose tissue, or insulin or glucose levels, are all possible mediators (4). Previously we have shown that both insulin and glucose levels attenuated some of the associations between body composition and arterial stiffness, but not all (4).

A limitation of the present study may be its crosssectional design. Firstly, the possibility that differences in body composition are the consequence rather than the cause of adiponectin concentrations cannot be excluded, but is unlikely as weight reduction affected adiponectin levels whereas adiponectin did not predict weight change $(49,50)$. Secondly, because we studied an older Caucasian population, it remains to be established whether the results also apply to other ethnicities and younger subjects. Thirdly, a relatively large part of the study population was lost because of the inability to acquire adequate ultrasound images due to obesity. If this did affect the results, however, it would probably lead to underestimations of the true associations. Finally, DXA cannot distinguish intraabdominal (or visceral) and abdominal s.c. adipose tissue. Additional studies are needed to explore the relative contributions of these and peripheral fat depots to adiponectin and arterial stiffness.

In conclusion, trunk fat and leg fat are strong, independent determinants of adiponectin concentrations, possibly due to differential adiponectin secretion by these fat depots. Furthermore, low adiponectin levels are associated with increased peripheral (but not central) arterial stiffness, particularly in subjects without prior CVD and type 2 diabetes. The association between body composition and peripheral arterial stiffness, however, was only partly explained by adiponectin concentrations, which may indicate that adiponectin may not be causally related to arterial stiffness or that factors other than adiponectin may be more important in the relationship between body composition and arterial stiffness. Inclusion of information on adiponectin isomer fractions may possibly increase our understanding of the mechanisms underlying our results. 


\section{Declaration of interest}

All authors declare that they have no conflict of interest.

\section{Funding}

This study was financially supported by The Netherlands Heart Foundation (grant no. 98.154), the Danish Research Council for Health and Disease, the Danish Diabetes Association, the Novo Nordisk Foundation, and Clinical Institute, Aarhus University, Aarhus, Denmark.

\section{Acknowledgements}

We thank Rosemarie van Eijck-Weel, Karen Mathiassen, and Hanne Petersen for their excellent technical assistance.

\section{References}

1 Folsom AR, Kushi LH, Anderson KE, Mink PJ, Olson JE, Hong CP, Sellers TA, Lazovich D \& Prineas RJ. Associations of general and abdominal obesity with multiple health outcomes in older women: the Iowa Women's Health Study. Archives of Internal Medicine 2000 160 2117-2128.

2 Westerhof N \& O'Rourke MF. Haemodynamic basis for the development of left ventricular failure in systolic hypertension and for its logical therapy. Journal of Hypertension 199513 943-952.

3 Ferreira I, Snijder MB, Twisk JW, van Mechelen W, Kemper HC, Seidell JC \& Stehouwer CD. Central fat mass versus peripheral fat and lean mass: opposite (adverse versus favorable) associations with arterial stiffness? The Amsterdam Growth and Health Longitudinal Study Journal of Clinical Endocrinology and Metabolism $2004892632-2639$.

4 Snijder MB, Henry RM, Visser M, Dekker JM, Seidell JC, Ferreira I, Bouter LM, Yudkin JS, Westerhof N \& Stehouwer CD. Regional body composition as a determinant of arterial stiffness in the elderly: the Hoorn Study. Journal of Hypertension 200422 2339-2347.

5 Lau DC, Dhillon B, Yan H, Szmitko PE \& Verma S. Adipokines: molecular links between obesity and atheroslcerosis. American Journal of Physiology. Heart and Circulatory Physiology $2005 \mathbf{2 8 8}$ H2031-H2041.

6 Cnop M, Havel PJ, Utzschneider KM, Carr DB, Sinha MK, Boyko EJ, Retzlaff BM, Knopp RH, Brunzell JD \& Kahn SE. Relationship of adiponectin to body fat distribution, insulin sensitivity and plasma lipoproteins: evidence for independent roles of age and sex. Diabetologia 200346 459-469.

7 Tanko LB, Bagger YZ, Alexandersen P, Larsen PJ \& Christiansen C. Central and peripheral fat mass have contrasting effect on the progression of aortic calcification in postmenopausal women. European Heart Journal 200324 1531-1537.

8 Snijder MB, Dekker JM, Visser M, Bouter LM, Stehouwer CD, Yudkin JS, Heine RJ, Nijpels G \& Seidell JC. Trunk fat and leg fat have independent and opposite associations with fasting and postload glucose levels: the Hoorn study. Diabetes Care 200427 372-377.

9 Kadowaki T, Yamauchi T, Kubota N, Hara K, Ueki K \& Tobe K. Adiponectin and adiponectin receptors in insulin resistance, diabetes, and the metabolic syndrome. Journal of Clinical Investigation $20061161784-1792$.

10 Szmitko PE, Teoh H, Stewart DJ \& Verma S. Adiponectin and cardiovascular disease: state of the art? American Journal of Physiology. Heart and Circulatory Physiology 2007292 H1655-H1663.

11 Kozakova M, Muscelli E, Flyvbjerg A, Frystyk J, Morizzo C, Palombo C \& Ferrannini E. Adiponectin and left ventricular structure and function in healthy adults. Journal of Clinical Endocrinology and Metabolism 200893 2811-2818.
12 Stork S, Bots ML, Angerer P, von Schacky C, Grobbee DE, Angermann CE \& Seufert J. Low levels of adiponectin predict worsening of arterial morphology and function. Atherosclerosis 2007194 147-153.

13 Araki T, Emoto M, Yokoyama H, Maeno T, Hatsuda S, Mori K, Koyama H, Shoji T, Inaba M \& Nishizawa Y. The association of plasma adiponectin level with carotid arterial stiffness. Metabolism $2006 \mathbf{5 5} 587-592$.

14 Mahmud A \& Feely J. Adiponectin and arterial stiffness. American Journal of Hypertension $2005 \mathbf{1 8} 1543-1548$.

15 Tentolouris N, Doulgerakis D, Moyssakis I, Kyriaki D, Makrilakis K Kosmadakis G, Stamatiadis D, Katsilambros N \& Stathakis C. Plasma adiponectin concentrations in patients with chronic renal failure: relationship with metabolic risk factors and ischemic heart disease. Hormone and Metabolic Research 200436 721-727.

16 Mooy JM, Grootenhuis PA, de Vries H, Valkenburg HA, Bouter LM, Kostense PJ \& Heine RJ. Prevalence and determinants of glucose intolerance in a Dutch caucasian population. The Hoorn Study. Diabetes Care 199518 1270-1273.

17 de Vegt F, Dekker JM, Jager A, Hienkens E, Kostense PJ, Stehouwer CD, Nijpels G, Bouter LM \& Heine RJ. Relation of impaired fasting and postload glucose with incident type 2 diabetes in a Dutch population: the Hoorn Study. Journal of the American Medical Association 2001285 2109-2113.

18 Frystyk J, Tarnow L, Krarup Hansen T, Parving HH \& Flyvbjerg A. Increased serum adiponectin levels in type 1 diabetic patients with microvascular complications. Diabetologia 200548 1911-1918.

19 Schram MT, Henry RM, van Dijk RA, Kostense PJ, Dekker JM, Nijpels G, Heine RJ, Bouter LM, Westerhof N \& Stehouwer CD. Increased central artery stiffness in impaired glucose metabolism and type 2 diabetes: the Hoorn Study. Hypertension $2004 \mathbf{4 3}$ $176-181$.

20 Henry RM, Kostense PJ, Spijkerman AM, Dekker JM, Nijpels G, Heine RJ, Kamp O, Westerhof N, Bouter LM \& Stehouwer CD. Arterial stiffness increases with deteriorating glucose tolerance status: the Hoorn Study. Circulation 2003107 2089-2095.

21 Kelly R \& Fitchett D. Noninvasive determination of aortic input impedance and external left ventricular power output: a validation and repeatability study of a new technique. Journal of the American College of Cardiology 199220 952-963.

22 Van Bortel LM, Balkestein EJ, van der Heijden-Spek JJ, Vanmolkot FH, Staessen JA, Kragten JA, Vredeveld JW, Safar ME, Struijker Boudier HA \& Hoeks AP. Non-invasive assessment of local arterial pulse pressure: comparison of applanation tonometry and echo-tracking. Journal of Hypertension $2001 \mathbf{1 9}$ $1037-1044$

23 Van Bortel LM, Duprez D, Starmans-Kool MJ, Safar ME, Giannattasio C, Cockcroft J, Kaiser DR \& Thuillez C. Clinical applications of arterial stiffness, Task Force III: recommendations for user procedures. American Journal of Hypertension 200215 $445-452$.

24 Henry RM, Kostense PJ, Bos G, Dekker JM, Nijpels G, Heine RJ, Bouter LM \& Stehouwer CD. Mild renal insufficiency is associated with increased cardiovascular mortality: the Hoorn Study. Kidney International 200262 1402-1407.

25 Spijkerman AM, Adriaanse MC, Dekker JM, Nijpels G, Stehouwer CD, Bouter LM \& Heine RJ. Diabetic patients detected by population-based stepwise screening already have a diabetic cardiovascular risk profile. Diabetes Care 200225 1784-1789.

26 Levey AS, Bosch JP, Lewis JB, Greene T, Rogers N \& Roth D. A more accurate method to estimate glomerular filtration rate from serum creatinine: a new prediction equation. Modification of Diet in Renal Disease Study Group. Annals of Internal Medicine 1999130 461-470.

27 Mazzali G, Di Francesco V, Zoico E, Fantin F, Zamboni G, Benati C, Bambara V, Negri M, Bosello O \& Zamboni M. Interrelations between fat distribution, muscle lipid content, adipocytokines, and insulin resistance: effect of moderate weight loss in older women. American Journal of Clinical Nutrition 200684 1193-1199. 
28 Nemet D, Wang P, Funahashi T, Matsuzawa Y, Tanaka S, Engelman L \& Cooper DM. Adipocytokines, body composition, and fitness in children. Pediatric Research 200353 148-152.

29 Zoico E, Di Francesco V, Mazzali G, Vettor R, Fantin F, Bissoli L, Guariento S, Bosello $\mathrm{O} \&$ Zamboni M. Adipocytokines, fat distribution, and insulin resistance in elderly men and women. Journals of Gerontology. Series A, Biological Sciences and Medical Sciences 200459 M935-M939.

30 Cote M, Mauriege P, Bergeron J, Almeras N, Tremblay A, Lemieux I \& Despres JP. Adiponectinemia in visceral obesity: impact on glucose tolerance and plasma lipoprotein and lipid levels in men. Journal of Clinical Endocrinology and Metabolism 200590 1434-1439.

31 Kwon K, Jung SH, Choi C \& Park SH. Reciprocal association between visceral obesity and adiponectin in healthy premenopausal women. International Journal of Cardiology $2005 \mathbf{1 0 1}$ 385-390.

32 Buemann B, Astrup A, Pedersen O, Black E, Holst C, Toubro S, Echwald S, Holst JJ, Rasmussen C \& Sorensen TI. Possible role of adiponectin and insulin sensitivity in mediating the favorable effects of lower body fat mass on blood lipids. Journal of Clinical Endocrinology and Metabolism 200691 1698-1704.

33 Tanko LB, Bruun JM, Alexandersen P, Bagger YZ, Richelsen B, Christiansen C \& Larsen PJ. Novel associations between bioavailable estradiol and adipokines in elderly women with different phenotypes of obesity: implications for atherogenesis. Circulation $20041102246-2252$.

34 Ritland LM, Alekel DL, Matvienko OA, Hanson KB, Stewart JW, Hanson LN, Reddy MB, Van Loan MD \& Genschel U. Centrally located body fat is related to appetitive hormones in healthy postmenopausal women. European Journal of Endocrinology 2008 158 889-897.

35 Motoshima H, Wu X, Sinha MK, Hardy VE, Rosato EL, Barbot DJ, Rosato FE \& Goldstein BJ. Differential regulation of adiponectin secretion from cultured human omental and subcutaneous adipocytes: effects of insulin and rosiglitazone. Journal of Clinical Endocrinology and Metabolism 200287 5662-5667.

36 Frystyk J, Berne C, Berglund L, Jensevik K, Flyvbjerg A \& Zethelius B. Serum adiponectin is a predictor of coronary heart disease: a population-based 10-year follow-up study in elderly men. Journal of Clinical Endocrinology and Metabolism 200792 571-576.

37 Sattar N, Wannamethee G, Sarwar N, Tchernova J, Cherry L, Wallace AM, Danesh J \& Whincup PH. Adiponectin and coronary heart disease: a prospective study and meta-analysis. Circulation $2006114623-629$.

38 Kanaya AM, Wassel Fyr C, Vittinghoff E, Havel PJ, Cesari M, Nicklas B, Harris T, Newman AB, Satterfield S \& Cummings SR. Serum adiponectin and coronary heart disease risk in older Black and White Americans. Journal of Clinical Endocrinology and Metabolism 200691 5044-5050.

39 Lawlor DA, Smith GD, Ebrahim S, Thompson C \& Sattar N. Plasma adiponectin levels are associated with insulin resistance but do not predict future risk of coronary heart disease in women. Journal of Clinical Endocrinology and Metabolism 200590 5677-5683.
40 Zoccali C, Mallamaci F, Tripepi G, Benedetto FA, Cutrupi S, Parlongo S, Malatino LS, Bonanno G, Seminara G, Rapisarda F, Fatuzzo P, Buemi M, Nicocia G, Tanaka S, Ouchi N, Kihara S, Funahashi T \& Matsuzawa Y. Adiponectin, metabolic risk factors, and cardiovascular events among patients with end-stage renal disease. Journal of the American Society of Nephrology 200213 134-141.

41 Kistorp C, Faber J, Galatius S, Gustafsson F, Frystyk J, Flyvbjerg A \& Hildebrandt P. Plasma adiponectin, body mass index, and mortality in patients with chronic heart failure. Circulation 2005 112 1756-1762.

42 George J, Patal S, Wexler D, Sharabi Y, Peleg E, Kamari Y, Grossman E, Sheps D, Keren G \& Roth A. Circulating adiponectin concentrations in patients with congestive heart failure. Heart 200692 1420-1424.

43 Pilz S, Mangge H, Wellnitz B, Seelhorst U, Winkelmann BR, Tiran B, Boehm BO \& Marz W. Adiponectin and mortality in patients undergoing coronary angiography. Journal of Clinical Endocrinology and Metabolism $2006914277-4286$.

44 Laughlin GA, Barrett-Connor E, May S \& Langenberg C. Association of adiponectin with coronary heart disease and mortality: the Rancho Bernardo study. American Journal of Epidemiology $2007 \mathbf{1 6 5} 164-174$.

45 Wannamethee SG, Whincup PH, Lennon L \& Sattar N. Circulating adiponectin levels and mortality in elderly men with and without cardiovascular disease and heart failure. Archives of Internal Medicine $2007 \mathbf{1 6 7} 1510-1517$.

46 Dekker JM, Funahashi T, Nijpels G, Pilz S, Stehouwer CD, Snijder MB, Bouter LM, Matsuzawa Y, Shimomura I \& Heine RJ. Prognostic value of adiponectin for cardiovascular disease and mortality. Journal of Clinical Endocrinology and Metabolism 200893 1489-1496.

47 Teoh H, Strauss MH, Szmitko PE \& Verma S. Adiponectin and myocardial infarction: a paradox or a paradigm? European Heart Journal 200627 2266-2268.

48 Rathmann W \& Herder C. Adiponectin and cardiovascular mortality: evidence for 'reverse epidemiology'. Hormone and Metabolic Research 200739 1-2.

49 Hotta K, Funahashi T, Arita Y, Takahashi M, Matsuda M, Okamoto Y, Iwahashi H, Kuriyama H, Ouchi N, Maeda K, Nishida M, Kihara S, Sakai N, Nakajima T, Hasegawa K, Muraguchi M, Ohmoto Y, Nakamura T, Yamashita S, Hanafusa T \& Matsuzawa Y. Plasma concentrations of a novel, adipose-specific protein, adiponectin, in type 2 diabetic patients. Arteriosclerosis, Thrombosis, and Vascular Biology 200020 1595-1599.

50 Yamamoto Y, Hirose H, Saito I, Nishikai K \& Saruta T. Adiponectin, an adipocyte-derived protein, predicts future insulin resistance: two-year follow-up study in Japanese population. Journal of Clinical Endocrinology and Metabolism 200489 87-90.

Received 28 November 2008

Accepted 15 December 2008 